\title{
Cooperación internacional y desarrollo: Reflexiones críticas
}

\author{
Josseling Lisbeth Osegueda Molina ${ }^{1}$
}

Primero que todo, es empezar a plantearnos que entendemos por desarrollo, y comprender, que el estar vinculado a temas de cooperación, desarrollo y proyectos, nos da una pauta para hacer algo por este mundo, que si bien no lo hemos concebido de la mejor manera por lo tanto su funcionamiento no es el más beneficioso. Para muchos estas son ideas fuera de la realidad y en ocasiones son consideradas utópicas, pero la existencia de estos grupos son realmente necesarios, ya que no podemos dejar que la organización del mundo se encuentre solo en manos de aquellos pocos. (Ojeda, 2016)

Si en realidad se quieren tratar temas de Cooperación Internacional y desarrollo, lo primero que se debe hacer es estudiar a fondo el tema. Por largos años las grandes escuelas de pensamiento nos han dicho que el desarrollo es equiparable al crecimiento económico, pero en estos tiempos ya sabemos que el desarrollo va más allá de esto. Hoy nos plantemos el enfoque de capacidades y el enfoque de derecho, pero aun así, el sustrato económico sigue ocupando un lugar muchos mayor que el resto de aspectos, con esto, no se quiere decir que el desarrollo económico no juegue un rol importante, en todo caso este sería parte de un tema, donde los seres humanos de todas partes del mundo alcancen una vida digna. Algo altamente discutible, ya que si cuestionamos este término de manera individual se obtendrían una variedad de repuestas. Ahí es donde radica la principal cuestión de debate en estos temas, hemos planteado un concepto. Hemos construido una idea de desarrollo y en consecuencia una idea de subdesarrollo, relacionándolo con algo negativo, con una situación no deseada que debemos de cambiar. Las preguntas en todo esto son:

¿Quién ha decidido que hay naciones en el mundo que se encuentran o son subdesarrolladas? ¿Por qué hemos asumidos esto como teorías infalibles?

¿Por qué asumir que cuando se trabaja en cooperación internacional el objetivo principal es el desarrollo?

¿De qué tipo de desarrollo estamos hablando?

¿Nos han consultado en algún momento que tipo de vida queremos tener?

Recibido: 08 de agosto de 2016

Aceptado: 20 de octubre de 2016

1 Estudiante de tercer año de Ciencias Políticas y Relaciones Internacionales. FAREM-Estelí, UNAN-Managua. Correo electrónico: josseling.osegueda@gmail.com 
Al parecer si nos hubiesen consultado la dirección del mundo el día de hoy sería distinta. Los grandes cuestionamientos que se hacen en este momento sobre las distintas teorías del desarrollo y subdesarrollo, las principales teorías fueron económicas y de ahí es donde se deriva la Economía del Desarrollo y posteriormente se incluyó la Sociología del desarrollo, nuestros orígenes plantearon que el desarrollo es una situación deseable que se encuentra en un lugar y para llegar ese lugar tenemos que subir una serie de peldaños y hacer una serie de cosas para llegar a ese lugar se puede tomar ese lugar como el espejo en el que nos habíamos reflejado para intentar lograr aquellas condiciones que tenían aquellos países que se consideraban desarrollados. A lo largo de nuestra historia hemos tenido un solo modelo de desarrollo y este ha sido el capitalista, un único modelo de producción y consume expandido a nivel universal, desde Occidente a todo el planeta. (Ojeda, 2016)

Las academias han justificado este concepto, por lo tanto la idea que tenemos de desarrollo es equiparable al crecimiento económico. Siendo de esta manera la Cooperación Internacional de desarrollo termina siendo un vehículo para que los países que se encuentran en subdesarrollo pasen a ser desarrollados, y si entendemos que el desarrollo es crecimiento económico, toda la cooperación estará dirigida hacia este. De ahí las teorías recalcando todo el tiempo que había que industrializarse, que modernizarse y pasar de esa cultura tradicional y por ende, para modernizarnos había que eliminar obstáculos institucionales, político, económicos y culturales para poder obtener este tipo de desarrollo. (Ojeda, 2016)

Esa partir de los años noventa donde se plantea una serie de enfoques críticos, es decir, que el modelo que se había expandido a nivel global llegara a su fin, en estos años cuando se empieza a escuchar hablar sobre desarrollo humano, es decir una nueva perspectiva acompañado de esto viene el pos desarrollo, las teorías des coloniales, el decrecimiento, las teorías poscoloniales con el fin de plantearnos que la idea de desarrollo que se nos ha enseñado no ha sido más que una forma manipulación, de interferencia cultural, creada en un lugar del mundo que de una u otra manera ha atravesado el mundo, en función de esto, si trabajamos por desarrollo, significa que no quedan alternativas para crear algo propio, con la única opción de destruir lo que teníamos, porque lo consideramos primitivo, tradicional y atrasado.

El querer buscar el estado ideal, como nos presentan el desarrollo ha causado que desestimemos nuestros saberes dejando atrás lo autóctono. La idea de descolonización del conocimiento, consiste en la superación del desarrollo, descolonizar el pensamiento, las leyes y la economía, empezar a descubrirnos y redescubrirnos tal y como somos, para plantear alternativas a ese desarrollo.

Estas teorías descolonizadores surgen de naciones que sufrieron la colonización, pero en este caso nos es América Latina quien da los mayores aportes, sino África, continente el cual se nos ha representado como aquel necesitado y urgido de la cooperación internacional para alcanzar el desarrollo, pero resulta que es aquí donde existe una escuela de pensamiento, que nos dice que 
la idea del desarrollo ha sido una idea totalmente colonizadora, una idea tan potente que nos distorsiona a nosotros mismos, si bien África necesita ayuda, pero Europa también la necesita, solo depende desde la lógica que la tomemos. (Ojeda, 2016)

Otra idea en cuestión es: ¿Que es el crecimiento? Normalmente este es asociado como algo positivo, un avance progresivo a un estado superior, mejor, de ahí otras interrogantes: ¿Hasta cuándo vamos a crecer? ¿Es viable nuestro modelo de crecimiento infinito? ¿Dónde vamos a llegar?

Entonces todos los cuestionamientos que se hacen partiendo de las teorías antes mencionadas nos llevan a que la idea del desarrollo es un mito, construido desde un lugar político y es una forma de dominación que solamente ha obstaculizado los procesos reales de desarrollo, porque han truncado el desarrollo social, cultural y hasta la propia capacidad de decidir la mejor forma de vida de los pueblos.

Al trabajar la Cooperación Internacional de desarrollo es evidente que desde su fundación se ha venido trabajando un modelo de vida único, para todo el planeta, aquí es necesario preguntarse si durante estos 70 años este modelo ha sido tan eficaz. Solo planteándonos estas inquietudes es cómo podemos ser creadores de proyectos apegados a la realidad.

Conocer la idea de vida que la gente realmente quiere, ya que en temas medioambientales y de género no hemos avanzado tanto.

Si bien ya se aprobaron los Objetivos de desarrollo del reto del milenio, en la cual se han tomado 15 años más para erradicarla pobreza de todo el mudo, lograr la igualdad, la preservación acuífera, etc., pero ¿Bajo qué modelo de producción y consume se basa nuestros modelos de desarrollo? Definitivamente no son sostenibles, si bien el modelo del buen vivir en Latinoamérica platea la recuperación de la cosmovisión indígenas, algo que fue visto por el desarrollo como un retraso o una dificultad, esto es algo difícil, es reubicar nuestros lugar en el planeta, que no somos la especie única ni central del mundo y esto es cambio de mentalidad brutal y todo lo que suene distinto choca de golpe. Su aplicación concreta es Bolivia Y Ecuador gracias a los gobiernos que han instalado en su constitución el Buen Vivir, tal vez no es plantearnos un solo modelo sino una agenda diversificada de como vivir y que así trabaje la cooperación internacional cambiando sus modelos de acción. (Ojeda, 2016)

Todo va a la idea que tenemos de desarrollo y hacia dónde queremos ir. Según el pos desarrollo nos dice que el desarrollo tiene que tener un fin, y afirma que el modelo productivo que hemos venido siguiendo por estos años es totalmente insostenible, que solo ha degenerado nuestro medioambiente y aumentado la desigualdad acompañada de pobreza ya que la no existe la coherencia política necesaria, el discurso es uno y la práctica es otra, acompañada de reglas de comercio totalmente injustas. 
Es solo cambiando la concepción de desarrollo es que cambiara la agenda de Cooperación Internacional, es decir, la evolución de nuestras ideas para lograr el cambio del sistema, es despertar al Gigante del Sur y el despertar de los pueblos lo que más se necesita en este momento. (Ojeda, 2016)

\section{Análisis sobre la ponencia}

En los últimos años se ha criticado aquello que conocemos como desarrollo, las razones son muchas y considero que cada una de ellas tiene bases sustentables para hacerlo. El desarrollo ha sido una idea impuesta, no es un término, o un concepto donde los todos países hayan participado en su elaboración. Aquí nos damos cuenta una vez más, que son pocos los países que gobiernan y definen el curso de la historia de la humanidad, son las grandes potencias o países que tienen incidencia alrededor del mundo.

Puede que suene ilógico cuestionar si el desarrollo es beneficioso, a primera vista podríamos decir que, además de beneficioso es necesario. Pero, si analizamos el modelo de Desarrollo que se ha venido implantando en las últimas décadas y revisamos detenidamente sus resultados, nos daremos cuenta que pesan más los aspectos negativos que positivos.

Las primeras teorías que dan soporte a este modelo son de carácter economicista porque el desarrollo se relacionaba estrechamente con el crecimiento económico, pero este va más allá, si bien se creó este modelo o sistema con la pretensión de cambiar el orden social, y reorganizar geopolíticamente el mundo, es una manera más de obtener el control y expandir el poder de la cultura Occidental, acompañada del capitalismo, y mantener vivo de manera disfrazada el colonialismo.

En los últimos veinte años, el desarrollo empezó a adquirir nuevas perspectivas, a esto podemos agregar la preocupación medioambiental, el cumplimiento de los derechos Humanos, le equidad de género y un sin número de cuestiones más que el mundo estaba padeciendo en ese momento, pero que solo unos pocos se animaban a expresar, y ahí surgen las propuestas de Desarrollo Integral, Desarrollo Sostenible y Desarrollo humano. Estos conceptos se crearon con la idea de querer aportar aspectos más humanistas, justos, tanto para las personas, como con el medioambiente.

Actualmente ninguno de estos tipos de desarrollo ha logrado al máximo su objetivo, porque existen limitantes que surgen de ciertos sectores, los más poderosos, para impedir la producción suficiente que necesitan las poblaciones para cubrir sus necesidades. Hoy es visible la inequidad existente en la distribución de recursos y es tangible la falta de oportunidades para que los individuos obtengan una vida prolongada, saludable y con derecho a la educación, en síntesis que gocen de la calidad de vida. 
No se puede hablar de desarrollo sin mencionar el papel que juegan los países subdesarrollados, los cuales no cuentan con las mismas características de un cierto grupo de países con más poder, este término dado a la mayoría de los países del sur, es tan excluyente como discriminante. Por otro lado, lo que conocemos como desarrollo se vuelve una idea sobrevalorada, se convierte un fin por el que todos los países "subdesarrollados" pretenden alcanzar, aunque esto incluya cambios drásticos o la eliminación de obstáculos de carácter cultural, político y social, para conseguir el desarrollo industrial y de este modo dar paso a lo que es la modernidad. En los años 90' surge la crítica al desarrollo por basarse en el crecimiento económico industrial, concentrándose en los efectos que estaba ocasionando a nivel ambiental y como lo que estaba en peligro no sólo era la naturaleza, sino la vida misma de los seres humanos.

Hablando de la cooperación Internacional para el Desarrollo, es lógico que esta se enfoque en el crecimiento económico, ya que esta, es la idea que ha sido implantada desde su origen por sus creadores, una meta muy difícil de alcanzar. Pero hay que tomar en cuenta que en el momento que se realizó este proceso no estuvo presente en las mesas de decisión ninguno de los países que estaban pasado crisis de todo tipo y quienes en realidad sabían que es lo que necesitaban para obtener una mejor vida.

Partiendo de esa desacreditación de conocimientos y cultura surgen nuevas teorías que nos ofrecen algo distinto y lo más interesante, como menciona la Dr. Ojeda, es el lugar de surgimiento de estas teorías, esta vez no le daremos el crédito a América Latina, sino a uno de los continente de donde la mayoría de sus países sufrieron los procesos viles de la colonización y en la actualidad se les considera como países subdesarrollados, hablamos de África, el cual muchas veces se le ha tildado como un dependiente de la Cooperación Internacional.

Puede haber algo de razón en esto, pero si el continente africano padece muchas crisis, se debe a la sobreexplotación de sus recursos que por muchas décadas los países ricos han generado. También hay que mencionar la desvalorización de la mano de obra de sus pobladores por las grandes transnacionales que tienen el control del mundo, ellos han obtenido su gran status de desarrollo a costa del empobrecimiento de estas naciones. Por lo tanto, es de admirarse, que un grupo pequeño de investigadores que cada vez toman más fuerza, nos propongan que ya basta de desarrollo, que es necesario detener los procesos de industrialización que están acabando con los recursos y generando mayor desigualdad alrededor del planeta.

Esto no quiere decir que debemos hacer un alto a las investigaciones que estén relacionas con el desarrollo, sino más bien intensificarlas, con la diferencia de que esta vez, no partan desde un grupo cerrado que no entienden lo que en realidad la gente quiere, sino que nazcan desde la población, de compartir sus vivencias y aprender de ellos para exportar sus conocimiento alrededor del mundo; ya que no solo nuestros países latinoamericanos y africanos necesitan ayuda, no solo existe pobreza y desigualdad en los países del sur, esta está vigente en el resto de los continentes, 
por tanto la Cooperación internacional es sustancia cuando se establece en múltiples direcciones de esta para que surjan un mejor efecto.

La Dr. Ojeda menciona que existe una sola agenda de Cooperación Internacional, algo que resulta incomprensible, ya que somos 194 países en el planeta, con más de 7 mil millones de personas, todas y cada una con características y capacidades diferentes. Esta agenda y modelo de vida en ningún momento fue consultado ni con la minoría de los países, por lo tanto, esta agenda no puede suplir las verdaderas dificultades o necesidades de las personas. El modelo actual de desarrollo excluye a la mayoría, y además desconoce los saberes propios de los pueblos, y desprecia el valor de la cultura y tradición local.

Es meritorio resaltar el papel que está jugando Bolivia y Ecuador, con su paradigma del Buen vivir. Estos dos países latinoamericanos se han convertido en estados plurinacionales, que poco a poco dejan atrás el modelo colonizador y manipulador del desarrollo, haciendo énfasis en la armonía con la naturaleza algo que retomaría los principios ancestrales de las culturas de la región, considerando al ser humano en un segundo plano frente al medio ambiente.

El querer Vivir Bien que significa empezar a valorar nuestra historia, nuestra música, nuestra vestimenta, nuestra cultura, nuestro idioma, nuestros recursos naturales, para recuperar lo nuestro, este paradigma hace distancia del socialismo y del capitalismo, ya que manifiesta que el primero solo busca a satisfacer las necesidades del hombre y el segundo, su objetivo principal es la acumulación del dinero, traducido en riquezas banales. Aquí se evidencia el cambio al que se quiere llegar.

Cabe destacar que si estos dos países han llegado hasta este punto ha sido por la decisiones de gobiernos progresistas que los lideran, así como la organización de la sociedad civil, lo que más se necesita del mundo, una complementación de distintos sectores, gobierno, población, un consenso aterrizado de los pueblos del mundo.

Es preciso evidenciar las consecuencias del modelo de desarrollo para darnos cuenta de que no estamos en el mejor de los caminos. Así, encontramos grandes reformas estructurales que han venido haciendo en los países llamados subdesarrollados y el deterioro que dejan en la capacidad de respuesta ante los compromisos de carácter internacional junto con la independización del crecimiento del comercio externo sin supervisión estatal, perdiendo así la eficiencia de las políticas nacionales. Cambios relacionados a la producción, el deterioro de la agricultura y los servicios sociales, llevándonos a una creciente inestabilidad económica, política y cultural. En la búsqueda de desarrollo, se han menoscabado las bases para un crecimiento fructífero, y se ha acentuado un modo de vivir dependiente de la intervención de ciertos actores cuyo objetivo y propósito es la dominación y sumisión de los países del sur. 


\section{CONCLUSIONES}

Esta más que claro cuáles han sido las pretensiones de los países que han impuesto el enfoque y modelo desarrollo desde sus inicios, y su opuesto, el subdesarrollo, se ha convertido en un problema que afecta todos los ámbitos de la vida social. Vemos la manifestación de un modelo que han provocado la perpetración del imperialismo y sus principales víctimas con los países del sur, que en la búsqueda de este ideal, han endeudado sus propios territorios, dejando como consecuencias, afectaciones en los distintos sectores de la sociedad civil.

Es indiscutible que si se quiere que la Cooperación Internacional actúe de forma más adecuada y apegada a la realidad, se tiene que cambiar la concepción del modelo de desarrollo, así como, la negatividad que percibimos al referirnos al subdesarrollo, se debe plantear en consenso, sobre las verdaderas insuficiencias que padecen los pueblos para generar cambios positivos.

Esto, es un tema de tomar conciencia, y de asumir responsabilidades; no se puede esperar a que las grandes potencias cambien el panorama de la situación; estas han tenido el tiempo y los medios necesarios, pero no lo han hecho, ya que no está en sus planes. Se necesita de la población, de una sociedad integrada y organizada, que tenga en primer lugar la apreciación de sus valores culturales, sus conocimientos y su tradición, con el fin de evitar la propagación del xenocentresimo, que nos ha perjudicado por largo tiempo.

No se puede esperar, que quienes promueven el modelo de desarrollo, se interesen por los países subdesarrollados, sus ayudas, que por lo general se traducen en préstamos solo postergan el endeudamiento de los países pobres y de esta manera aseguran su manipulación. Ahora, ¿Cómo pueden los países subdesarrollados superar esta manipulación? La respuesta es, integración regional; fuerte y con el valor suficiente para tomar ventaja en el plano internacional, capaz de descolonizar los conocimientos implantados, expresar las necesidades que afectan a nuestra población y que se caracterice por ser creadora soluciones y alternativas para mejorar la calidad de vida de nuestros pueblos.

\section{BIBLIOGRAFÍA}

Ojeda, T. (28 de Enero de 2016). Ciclo de Reflexiones: Cooperacion internacional y desarrollo: Reflexiones criticas. Obtenido de https://www.youtube.com/watch?v=vhcyjX0Sox8 